\title{
Ovulation from rat and hamster ovaries in vitro
}

\author{
P. Osman and C. Lieuwma-Noordanus \\ Department of Anatomy, Erasmus University, Rotterdam, The Netherlands
}

\begin{abstract}
Summary. The ovaries of pro-oestrous rats (pubertal and adult) and hamsters were explanted in toto at various times after the preovulatory gonadotrophin surge to obtain endogenously stimulated ovaries. Subnormal numbers of ovulations from pubertal and adult rat ovaries were found when incubation was started during the period from $17: 00$ to $24: 00 \mathrm{~h}$ on the day of pro-oestrus. Normal numbers of ovulations only occurred from rat ovaries in vitro when incubation was started at $01: 00 \mathrm{~h}$, i.e. when ovulation had already begun in vivo. In contrast, full ovulation from hamster ovaries was observed in vitro after incubation at 22:00 h and later, although the ovulatory process had not started in vivo. This difference in the ability of rat and hamster follicles to ovulate in vitro could be due to a different role of the accumulation of tissue fluid for the mechanism of ovulation.
\end{abstract}

\section{Introduction}

Ovulation in vitro has been reported for whole ovaries and ovarian fragments of mice (Fritz, Cho \& Biggers, 1965; Baker \& Neal, 1972), but only after hormonal pretreatment and/or addition of hormones to the culture media. However, ovulation in vitro has been observed for hamster ovaries without hormonal pretreatment and with a higher ovulation rate if progesterone was added to the medium (Baranczuk \& Fainstat, 1976). Ovulation has not been demonstrated for rat ovaries in vitro and the present experiments were therefore designed to investigate whether ovulation could occur from whole rat ovaries in vitro. Ovaries of pro-oestrous rats (pubertal and adult) were used after the preovulatory gonadotrophin surge to obtain endogenously stimulated ovaries. Ovaries of pubertal rats were used because they differ slightly in the ovulatory process from the ovaries of adults (Osman, 1975) and may also behave differently under in-vitro conditions because of the absence of old corpora lutea.

The suitability of the experimental conditions was checked by comparison with the ovaries of pro-oestrous hamsters since they have been shown to be able to ovulate in vitro (Baranczuk \& Fainstat, 1976).

\section{Materials and Methods}

Pubertal and adult rats of the R-Amsterdam strain (a Wistar substrain) were used. They were weaned at 22 days of age. First pro-oestrus in pubertal rats was detected as reported by Osman (1975). Body weight at first pro-oestrus was $80-100 \mathrm{~g}$, age range $35-41$ days. The adult rats used were 2-3 months of age and weighed 150-200 g. They were used only after exhibiting 3 consecutive 5-day cycles. Adult Syrian hamsters, 2-3 months of age and weighing 80-120 g, were used after 3 consecutive 4-day cycles; cyclicity was determined by recording the day of conspicuous vaginal discharge occurring on the morning after ovulation (= Day 1). All animals were kept in temperature-controlled rooms $\left(23 \pm 2^{\circ} \mathrm{C}\right)$ which were lit from 05:00 to 19:00 $\mathrm{h}$. 


\section{Experiment 1}

Explantation of the ovaries was carried out following ether anaesthesia at 17:00, 20:00, 22:00, 23:00, 24:00 and 01:00 $\mathrm{h}$ in the rats after pro-oestrus had been determined from vaginal smears in the morning, and in the hamster at the same times during the evening and night before the expected day of vaginal discharge (i.e. Day 4). From each animal one randomly chosen ovary was removed, weighed and fixed in Bouin's fluid. The remaining ovary was immediately transferred to a culture vessel and submerged in 1-2 $\mathrm{ml}$ of the chemically defined medium TC 199 (Fainstat, 1972). The culture vessels were kept in a Dubnoff incubator (shaking frequency $175 / \mathrm{min}$ ), and gassed with $95 \% \mathrm{O}_{2}: 5 \% \mathrm{CO}_{2}$ at a temperature of $34^{\circ} \mathrm{C}$. These conditions were similar to those used by Baranczuk \& Fainstat (1976). Incubation was terminated at 10:00 h the next morning and the ovaries were then weighed and fixed as described above.

The contralateral non-incubated ovaries and ovaries from two additional groups of animals killed at 10:00 h on the day of pro-oestrus and at 10:00 h on the day of oestrus served as in-vivo controls.

\section{Experiment 2}

Both ovaries from rats (pubertal and adult) and hamsters at pro-oestrus were explanted and incubated at 22:00 h and about equal numbers of randomly chosen ovaries of each animal group were taken out of the incubator at 24:00, 02:00 and 04:00 h. The ovaries were weighed and fixed as described previously.

\section{Histology}

All ovaries were embedded in paraffin wax and serial $10 \mu \mathrm{m}$ sections were made for histological examination. The occurrence and numbers of ovulations were assessed from the presence of freshly ruptured follicles with normal peripheral stigmata and without oocytes or from the presence of young corpora lutea, of normal appearance and not containing oocytes. The follicles classified as 'not ovulating' and 'ovulating' are illustrated in Plate 1. Preliminary experiments showed that although eggs were detected in the incubation vessels, the number

\section{PLATE 1}

Fig. 1. Hamster ovary, incubated from $20: 00 \mathrm{~h}$ on the day of pro-oestrus until 10:00 h the next morning, showing a preovulatory follicle with an ovum trapped at the entrance to the stigma. This type of follicle was classified as 'not ovulating'. $\times 90$.

Fig. 2. Adult rat ovary, incubated from $22: 00 \mathrm{~h}$ on the day of pro-oestrus until 10:00 $\mathrm{h}$ the next morning, showing a 'not ovulating' follicle; part of the cumulus cell mass has been expelled. $\times 90$.

Fig. 3. Pubertal rat ovary, incubated from $22: 00 \mathrm{~h}$ on the day of pro-oestrus until 10:00 $\mathrm{h}$ the next morning, showing a fresh corpus luteum sectioned through the stigma. The expelled egg, still attached to the ovarian surface, showed pyknosis in the cumulus cells. This type of follicle was classified as 'ovulating'. $\times 90$.

Fig. 4. Pubertal rat ovary, incubated from $22: 00 \mathrm{~h}$ on the day of pro-oestrus until $04: 00 \mathrm{~h}$ the next morning, showing an 'ovulated' follicle freshly ruptured and with an open stigma. $\times 90$.

Fig. 5. The same ovary as in Fig. 4 showing an ovum still surrounded by cumulus cells. This egg was found 25 sections away from the stigma shown in Fig. 4. $\times 90$. 
PLATE 1
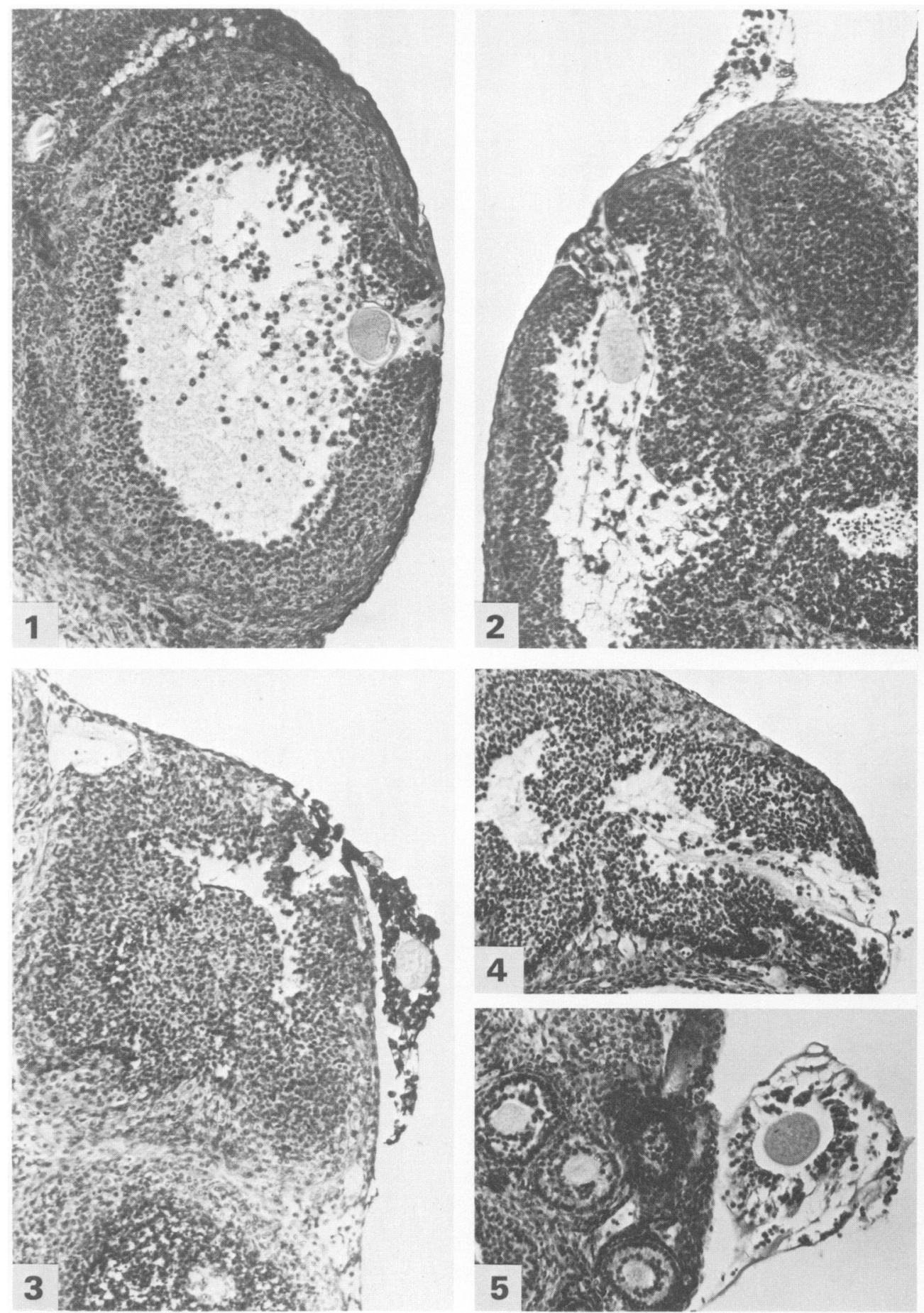

(Facing p. 432) 
found was unreliable as a measure for ovulation in vitro: hamster ovaries $(n=5)$ incubated from $22: 00 \mathrm{~h}$ on the day of pro-oestrus until 10:00 h the next morning showed $5.4 \pm 0.2$ fresh corpora lutea whereas only $2.6 \pm 0.4 \mathrm{eggs}$ were found in the incubation vessels.

The degree of ovulation was expressed as an ovulation index: (no. of ovulating ovaries/no. of ovaries used) $\times$ (mean no. of ovulations per ovulating ovary/normal mean no. of ovulations per ovary). Based on earlier findings with this strain of rat (Osman, 1975; Osman \& Dullaart, 1976), the normal mean number of ovulations per ovary was considered to be 5 for pubertal and adult rats. The same number was used for the hamster (Kent, 1968). An ovulation index of 0.80-1.25 was considered normal.

\section{Statistical analyses}

Values are given as mean \pm s.e.m. In Exp. 1 data were assessed by analysis of variance (Winer, 1971). If a significant overall difference was found, data were further analysed with Duncan's New Multiple range test. A difference was considered significant if $P \leqslant 0.05$. In Exp. 2 the Wilcoxon two-sample test was used and a difference was considered significant if the double-tail probability was $\leqslant 0 \cdot 05$.

\section{Results}

\section{Experiment 1}

In-vitro observations. After incubation of ovaries from animals at pro-oestrus, ovulations were found the next morning at 10:00 h for all rat ovaries except for the pubertal ones explanted at 17:00 h (Table 1). However, the numbers of ovulations were mostly below normal. Normal numbers of ovulations (ovulation index of $0.80-1.25$ ) were only observed when ovaries were explanted at $01: 00 \mathrm{~h}$, a time at which ovulation had already started in vivo. Hamster ovaries showed normal numbers of ovulations when explanted at $22: 00 \mathrm{~h}$ or later (ovulation index $1 \cdot 00-1 \cdot 24)$.

Incubation of pubertal and adult rat ovaries caused significant weight loss independent of the time of onset of incubation. At the end of incubation $(10: 00 \mathrm{~h})$ ovarian weight in all groups was significantly $(P<0.05)$ less than that in the control animals killed at that time: for all incubated groups combined the weights were $13.2 \pm 0.4 \mathrm{mg}(n=39)$ for pubertal rats and $16.1 \pm 0.3 \mathrm{mg}$ $(n=34)$ for adult rats compared with values of $20.0 \pm 0.4 \mathrm{mg}(n=12)$ and $19.2 \pm 0.6 \mathrm{mg}$ $(n=8)$ respectively for the in-vivo controls. The incubated hamster ovaries only showed significant weight loss $(11.4 \pm 0.6 \mathrm{mg}, n=13)$ compared to the values for the in-vivo control ovaries $(13.7 \pm 0.4 \mathrm{mg}, n=8)$ if they were explanted before $22: 00 \mathrm{~h}$.

Table 1. The effect of incubation on ovulation in rat and hamster ovaries

\begin{tabular}{|c|c|c|c|c|c|c|}
\hline \multirow{3}{*}{$\begin{array}{l}\text { Start of } \\
\text { incubation } \\
\text { (h) }\end{array}$} & \multicolumn{6}{|c|}{ Ovulation* (ovulation index) } \\
\hline & \multicolumn{3}{|c|}{ Ovaries in vivo at start of incubation } & \multicolumn{3}{|c|}{ Ovaries in vitro at end of incubation $(10: 00 \mathrm{~h})$} \\
\hline & $\begin{array}{l}\text { Pubertal } \\
\text { rat }\end{array}$ & $\begin{array}{l}\text { Adult } \\
\text { rat }\end{array}$ & Hamster & $\begin{array}{c}\text { Pubertal } \\
\text { rat }\end{array}$ & $\begin{array}{c}\text { Adult } \\
\text { rat }\end{array}$ & Hamster \\
\hline $17: 00$ & $0 / 5(0)$ & $0 / 5(0)$ & $0 / 5(0)$ & $0 / 5(0)$ & $2 / 5(0.05)$ & $1 / 5(0.20)$ \\
\hline $20: 00$ & $0 / 5(0)$ & $0 / 6(0)$ & $0 / 8(0)$ & $5 / 5(0.76)$ & $5 / 6(0.60)$ & $6 / 8(0.20)$ \\
\hline $22: 00$ & $0 / 8(0)$ & $0 / 5(0)$ & $0 / 6(0)$ & $6 / 8(0.30)$ & $4 / 5(0.51)$ & $6 / 6(1.00)$ \\
\hline $23: 00$ & $0 / 7(0)$ & $1 / 6(0.03)$ & $1 / 7(0.03)$ & $7 / 7(0.60)$ & $5 / 6(0.47)$ & $7 / 7(1 \cdot 12)$ \\
\hline $24: 00$ & $1 / 6(0.07)$ & $1 / 6(0.03)$ & $0 / 6(0)$ & $5 / 6(0.50)$ & $6 / 6(0.46)$ & $6 / 6(1 \cdot 10)$ \\
\hline 01:00 & $7 / 8(0.42)$ & $2 / 6(0.07)$ & $5 / 6(0.30)$ & $8 / 8(0.84)$ & $6 / 6(0.96)$ & $6 / 6(1 \cdot 24)$ \\
\hline
\end{tabular}

* No. of ovulating ovaries/total no. of ovaries. 
In-vivo observations. A significant overall change of the relative weight of the ovaries during the period between 10:00 h on the days of pro-oestrus and oestrus was found in pubertal rats and adult rats and hamsters (Text-fig. 1). The change was most marked in the pubertal rats. Ovulation started in all three groups close to the time at which maximum ovarian weight was reached.

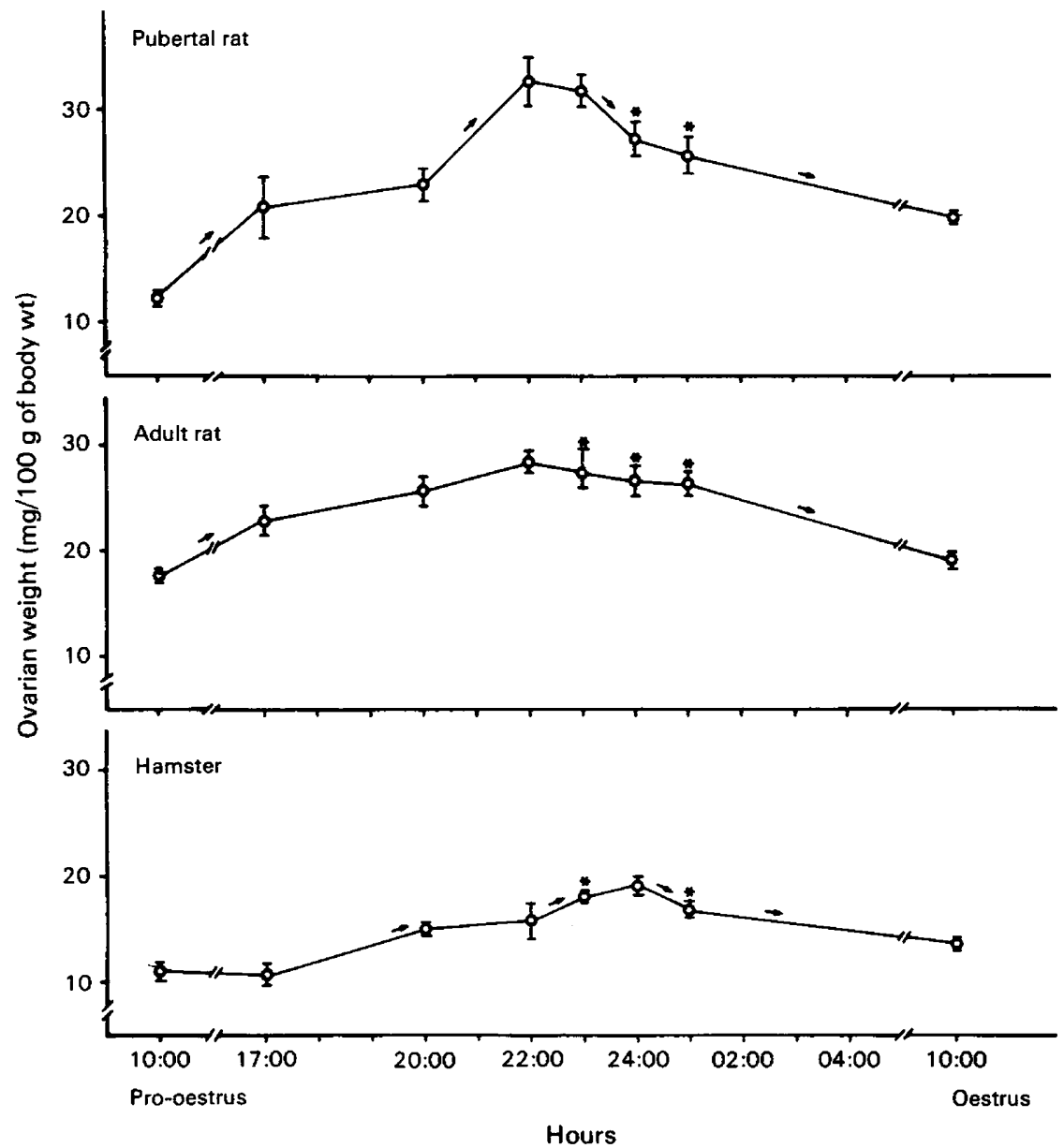

Text-fig. 1. Relative ovarian weights of pubertal rats, adult rats and hamsters during pro-oestrus and early oestrus. Each point represents the mean \pm s.e.m. derived from 5-8 ovaries. Arrows indicate a significant increase or decrease, and the asterisks $\left(^{*}\right)$ times when ovulation was observed.

\section{Experiment 2}

In this experiment ovulation seemed to start slightly earlier in vitro than in vivo in both groups of rats but not in the hamsters (Table 2). However, a definite delay of the ovulatory process was observed in vitro. It was most marked at $02: 00 \mathrm{~h}$ in pubertal rats, at 04:00 h in adult rats and at both 02:00 and 04:00 $\mathrm{h}$ in the hamster.

Loss of ovarian weight during incubation was also noted in this experiment. At 24:00, 02:00 and 04:00 h ovarian weight was significantly less in all types of animals in the incubated ovaries than in the in-vivo control ovaries. By $24: 00 \mathrm{~h}$ ovarian weight in pubertal rats $(16.5 \pm 0.8 \mathrm{mg}$, $n=5$ ) was significantly less than that at the beginning of incubation $(32.8 \pm 2.2 \mathrm{mg}, n=8)$ and 
Table 2. The effect on ovulation of short-term incubation of rat and hamster ovaries from 22:00 h on the day of pro-oestrus

\begin{tabular}{|c|c|c|c|c|c|c|}
\hline \multirow{3}{*}{$\begin{array}{l}\text { End of } \\
\text { incubation } \\
\text { (h) }\end{array}$} & \multicolumn{6}{|c|}{ Ovulation* (ovulation index) } \\
\hline & \multicolumn{2}{|c|}{ Pubertal rat } & \multicolumn{2}{|c|}{ Adult rat } & \multicolumn{2}{|c|}{ Hamster } \\
\hline & In vivo & In vitro & In vivo & In vitro & In vivo & In vitro \\
\hline $24: 00$ & $0 / 4(0.00)$ & $2 / 5(0.08)$ & $0 / 8(0.00)$ & $2 / 6(0.07)$ & $4 / 8(0.12)$ & $3 / 8(0.13)$ \\
\hline $02: 00$ & $4 / 4(0.84)$ & $2 / 5(0.20)$ & $1 / 6(0.03)$ & $2 / 6(0 \cdot 13)$ & $8 / 8(1 \cdot 12)$ & $4 / 8(0 \cdot 15)$ \\
\hline 04:00 & $4 / 6(0.64)$ & $3 / 4(0.60)$ & $6 / 6(0 \cdot 60)$ & $3 / 6(0.25)$ & $6 / 6(0.96)$ & $3 / 8(0 \cdot 10)$ \\
\hline
\end{tabular}

- No. of ovulating ovaries/total no. of ovaries.

that of in-vivo controls at $24: 00 \mathrm{~h}(25 \cdot 0 \pm 1 \cdot 4, n=4)$. The comparable data for adult rats were $18.6 \pm 0.9 \mathrm{mg}(n=6)$ at $24: 00 \mathrm{~h}, 28.3 \pm 1.0 \mathrm{mg}(n=5)$ at the start of incubation and $25.4 \pm 1.6 \mathrm{mg}(n=8)$ in the controls. In the hamster the values were $14.8 \pm 0.8 \mathrm{mg}(n=8)$ at $24: 00 \mathrm{~h}, 15.8 \pm 1.4 \mathrm{mg}(n=6)$ (not significant) at the start of incubation and $17.4 \pm 0.6 \mathrm{mg}$ $(n=8)$ for the controls.

\section{Discussion}

The present results demonstrate the suitability of the in-vitro system used by confirming the findings of Baranczuk \& Fainstat (1976) that hamster ovaries are able to ovulate in vitro. Our experiments, even without the addition of progesterone, gave better results in terms of the ovulation index than did those of Baranczuk \& Fainstat (1976). This difference in results could be due to the incubation system used and/or to a difference in assessing the number of ovulations. Baranczuk \& Fainstat (1976) probably judged the number of ovulations from the number of ova found in the media, but such ova could have remained unnoticed if they stuck to the wall of the incubation vessel or remained attached to the ovarian surface as shown in Pl. 1, Figs 3 and 5 . The rather constant number of ovulations at various times after incubation suggests that it is unlikely that the ovulation number in our experiments was higher because of mechanical damage of the follicles during explantation or the shaking procedure. The present experiments have also shown that the ovaries of pubertal and adult rats are able to ovulate in vitro. However, in contrast to hamster ovaries for which normal numbers of ovulations were found if incubation started at $22: 00 \mathrm{~h}$ or later, full ovulation was only obtained when the rat ovaries were explanted at the time ovulation had already started in vivo, i.e. 01:00 h.

Although many factors are involved in the process of expulsion of the eggs from a follicle, the data on ovarian weight may provide one possible explanation of the different findings for rat and hamster ovaries. In the rat, ovarian weight in vivo showed a definite preovulatory increase, whereas in the hamster this increase was smaller and also started later. Moreover, incubation interfered with this increase in weight most markedly in the rat. In the hamster' incubation of ovaries from $22: 00 \mathrm{~h}$ only slightly affected ovarian weight (see e.g. Exp. 2). The rapid preovulatory increase in ovarian weight must be due to an increase in tissue fluid derived from the blood and thus dependent on an intact vascularization. This accumulation of tissue fluid cannot develop in vitro. If physiological oedema is indeed involved in ovulation, this oedema would then be important for full ovulation in the hamster only from 20:00 to 22:00 $\mathrm{h}$ whereas in the rat this oedema has to be maintained until the very start of the ovulatory process.

A double role for this oedemal fluid has been suggested (Burr \& Davies, 1951): firstly, interstitial oedema in the medullary region of the ovary could exert pressure on the preovulatory follicles and thus bring them to the ovarian surface; secondly the oedema could be instrumental in causing avascular areas (stigmata) at the ovarian surface. If there is a causal relationship 
between the normal process of ovulation and the presence of accumulated tissue fluid, our results would indicate that the physiological importance of this oedema is different in rat and hamster. It is conceivable that in the hamster all follicles destined to ovulate are already located at the periphery of the ovary by $22: 00 \mathrm{~h}$, whereas in the rat only some of the follicles have reached the peripheral area at this time. This would explain the absence of full ovulation from rat ovaries after incubation starting before $01: 00 \mathrm{~h}$. The possibility that other unknown factors, related to the incubation procedure, act differently on rat and hamster ovarian tissue cannot be excluded. However, treatment in vivo of pro-oestrous pubertal and adult rats with indomethacin reduced accumulation of fluid in the ovary and caused a disturbance in the ovulatory process: eggs were released into the ovarian interstitium (Osman, 1977; Osman \& Dullaart, 1976). The difference in interference with the physiological ovarian oedema between the indomethacin experiment and the present (in-vitro) study may account for the different way of disturbance of ovulation.

We thank Professor J. Moll and Dr H. M. A. Meijs-Roelofs for constructive criticism during the preparation of the manuscript and Dr W. J. de Greef for help with the statistical analyses.

\section{References}

Baker, T.G. \& Neal, P. (1972) Gonadotrophin-induced maturation of mouse Graafian follicles in organ culture. In Oogenesis, pp. 377-396. Eds J. D. Biggers \& A. W. Schuetz. University Park Press, Baltimore.

Baranczuk, R.J. \& Fainstat, T. (1976) Progesteroneinduced ovulation of the hamster ovary in vitro. $J$. Endocr. 70, 317-318.

Burr, J.H., Jr \& Davies, J.J. (1951) The vascular system of the rabbit ovary and its relationship to ovulation. Anat. Rec. 111, 273-297.

Fainstat, T. (1972) Submerged organ culture: an improved method. In Vitro 7, 300-303.

Fritz, H.I., Cho, W.K. \& Biggers, J.D. (1965) Ovulation from whole ovaries of mice in organ culture. $J$. Cell Biol. 27, 31A.
Kent, G.C., Jr (1968) Physiology of reproduction. In The Golden Hamster, pp. 119-138. Eds R. A. Hoffman, P. E. Robinson \& H. Magalhaes. Iowa State University Press, Ames.

Osman, P. (1975) Preovulatory changes in the ovaries during the first spontaneous pro-oestrus in the rat. $J$. Endocr. 67, 259-265.

Osman, P. (1977) Ovarian changes during first spontaneous ovulation in intact and indomethacin treated rats. Endokrinologie 69, 351-354.

Osman, P. \& Dullaart, J. (1976) Intraovarian release of eggs in the rat after indomethacin treatment at pro-oestrus. J. Reprod. Fert. 47, 101-103.

Winer, B.J. (1971) Statistical Principles in Experimental Design. McGraw-Hill Book Company, New York.

Received 8 November 1979 